\title{
Small subunit ribosomal RNA of Blastomyces dermatitidis: sequence and phylogenetic analysis
}

\author{
Antonia Geber, ${ }^{1, *}$ Desmond E. Higgins, ${ }^{2}$ Andrew P. Waters,${ }^{3}$ John E. BennetT ${ }^{1}$ and \\ THOMAS F. MCCUTCHAN ${ }^{1}$ \\ ${ }^{1}$ Laboratory of Clinical Investigation and Laboratory of Parasitic Diseases, National Institute of Allergy and Infectious \\ Diseases, National Institutes of Health, Bethesda, MD 20892, USA \\ ${ }^{2}$ European Molecular Biology Laboratory, Heidelberg, FRG \\ ${ }^{3}$ Laboratorium voor Parasitologie, Universiteit Te Leiden, Postbus 9605, 2300 RC Leiden, The Netherlands
}

(Received 29 August 1991; accepted 23 October 1991)

\begin{abstract}
We determined the small subunit (18S) ribosomal RNA sequence of the dimorphic fungus Blastomyces dermatitidis. The sequence was compared to that of fourteen other eukaryotic organisms, ten of which were higher fungi, and an evolutionary tree was constructed based on these sequences. $B$. dermatitidis aligned most closely with the Ascomycetes Neurospora crassa and Podospora anserina, in agreement with previous phylogenetic analysis based on morphological criteria. Phase-specific cDNA clones derived by reverse transcription of RNA isolated from the yeast and mycelial phases of $B$. dermatitidis were also sequenced. The $18 S$ ribosome sequence was found to be the same in both phases. Heterogeneity was found at both the genomic and RNA level at position 1352.
\end{abstract}

\section{Introduction}

Studies of the evolution of fungi and their phylogenetic relationships have most often been based on biochemistry and morphology, including ultrastructure. Recent attempts to clarify fungal taxonomy have, however, used molecular data obtained from ribosomal nucleotide sequences (Foerster et al., 1990; Gunderson et al., $1987 a$ ). These molecules are well suited as taxonomic tools as they are universally present and, because of their function in protein synthesis, are highly conserved. The large size of the small subunit (SSU) rRNA (16-18S) makes it particularly well suited as an indicator of phylogeny (Olsen et al., 1986). In this paper, we report the sequence of the SSU rRNA of the dimorphic fungus Blastomyces dermatitidis, and construct an evolutionary tree based on this sequence and that of fourteen other eukaryotic organisms.

$B$. dermatitidis is the aetiological agent of blastomycosis, a multisystem illness whose pathogenesis involves inhalation of conidia and transformation to the

\footnotetext{
- Author for correspondence. Tel. (310) 496 3461; fax (301) 4800050.

The nucleotide sequence data reported in this paper have been submitted to GenBank and have been assigned the accession number M63096.
}

yeast phase, followed by localized or disseminated disease. Dimorphism in $\boldsymbol{B}$. dermatitidis is thermally regulated (Levine \& Ordal, 1949). Differences in cell wall polysaccharide (Kanetsuna \& Carbonell, 1971), protein composition (Roy \& Landau, 1972), and rates of oxygen consumption (Nickerson \& Edwards, 1949) have been described between the two phases. The amount of RNA has been found to differ between the yeast and the mycelial phase (Taylor, 1961), and two reports have suggested a difference in ribosomal size in dimorphic fungi (Gates \& Brownstein, 1980; Bawdon et al., 1984). In Plasmodium, structurally distinct SSU rRNAs are known to exist at different stages of the parasite's life cycle (Gunderson et al. 1987b). We investigated the possibility that stage-specific SSU rRNA may exist in $B$. dermatitidis and be involved in the molecular events underlying the regulation of morphogenesis.

\section{Methods}

Cultures. B. dermatitidis (ATCC 26199) cultures were grown on brain heart infusion (BHI) media with $2 \%$ glucose. Yeast cells were grown on BHI agar at $37^{\circ} \mathrm{C}$ for both DNA and RNA extraction. Hyphal cells were grown at $30^{\circ} \mathrm{C}$ on $\mathrm{BHI}$ agar for DNA extraction and in BHI broth with constant agitation for RNA extraction. E. coli DH5amax (Bethesda Research Laboratories) was the recipient for bacterial transformation. 
Isolation of nucleic acids. Yeast and hyphal cells were pelleted and washed with $1 \mathrm{M}-\mathrm{NaCl}$. Cells were broken by vortexing for 3-4 $30 \mathrm{~s}$ intervals with $0.45 \mathrm{~mm}$ glass beads (PGC) for RNA extraction and $4 \mathrm{~mm}$ glass beads (PGC) for DNA extraction. The samples were kept on ice between vortexing. RNA was extracted by the method of Chomczynski (1987). Prior to DNA extraction, cells were lyophilized and stored at $-20^{\circ} \mathrm{C}$. DNA was extracted in a sucrose buffer with $1 \mathrm{M}$ sarcosate (ICN Biochemicals) and $1 \mathrm{M}$-sodium percholate (Fischer Scientific) by the method of Price (1978). Following two extractions with chloroform/isoamyl alcohol $(24: 1 ;$ J. T. Baker Chemical) the aqueous phase was placed over a caesium chloride (optical grade; ICN Biochemicals) gradient and centrifuged at 45000 r.p.m. for $20-22 \mathrm{~h}$. The DNA band was removed, extracted with butanol, and dialysed against $10 \mathrm{~mm}$-Tris/1 mM-EDTA (TE) for $2 \mathrm{~h}$. DNA was precipitated in ethanol, washed with $70 \%$ ethanol, and resuspended in TE.

Restriction enzyme digestion and Southern blot analysis. Genomic DNA was digested with EcoRI, XbaI, HindIII, and SphI restriction endonucleases (BRL) according to the manufacturer's instructions. Fragments were separated by electrophoresis through a $0.8 \%$ agarose gel. DNA was transferred to nylon membranes (Dupont) by the method of Southern (1975). Nylon blots were hybridized to oligonucleotides complementary to conserved areas of $18 \mathrm{~S}$ ribosome which had been end-labelled with $\left.{ }^{32} \mathrm{P}\right] \gamma \mathrm{ATP}$ (Amersham) using T4 polynucleotide kinase (BRL).

Cloning and sequencing. Phase-specific cDNA clones of the SSU rRNA were obtained in the following manner. First strand cDNA was synthesized using the MMLV reverse transcriptase enzyme (BRL) and primers complementary to a conserved region of the $3^{\prime}$ end of the SSU rRNA as described by Sambrook et al. (1989). The sample was heated to $95^{\circ} \mathrm{C}$ for $5 \mathrm{~min}$ and amplified by the polymerase chain reaction (PCR) using primers containing EcoRI sites complementary to conserved areas at the $5^{\prime}$ and $3^{\prime}$ ends of the SSU rRNA. The PCR product was digested with EcoRI (BRL), electrophoresed in low melting agarose gel, excised from the gel, and ligated into pUC19. Ligated material was transformed into $E$. coli DH5 $\alpha$ max.

Genomic clones were obtained from EcoRI fragments, size selected based on Southern analysis, and ligated into pUC19. Ligation products were transformed into $E$. coli DH5 $\alpha$ max. Transformants were screened with radiolabelled oligonucleotide complementary to conserved areas of the SSU rRNA. Plasmid isolation was carried out by a modified method of Holmes \& Quigley (1988). Following denaturation with $2 \mathrm{M}-$ $\mathrm{NaOH}$, plasmid DNA sequencing was performed by the dideoxynucleotide chain-termination method according to the instructions of the Sequenase kit (United States Biochemicals). Seven cDNA clones derived from each of the mycelial and yeast phases were sequenced. The genomic sequence was determined from both strands.

Phylogenetic analysis. The SSU rRNA sequences of Physarum polycephalum (Johansen et al., 1988), Dictyostelium discoideum (McCarroll et al., 1983), Lagenidium giganteum, Phytophthora megasperma, Blastocladiella emersonii (Foerster et al., 1990), Neurospora crassa (Sogin, 1986), Candida albicans (Hendricks et al., 1990), Kluyveromyces marxianus var. lactis (Maleszka \& Clark-Walker, 1990), Saccharomyces cerevisiae (Rubtsov et al., 1980), Torulaspora delbrueckii (Hendriks et al. 1990) and Torulopsis glabrata (Wong \& Clark-Walker, 1990) have been reported elsewhere. The sequences of Mucor racemosus, Podospora anserina, and Schizosaccharomyces pombe (Sogin, unpublished) were obtained from the EMBL nucleotide sequence data base. The SSU rRNA of $B$. dermatitidis was aligned with these sequences using the CLUSTAL $\vee$ package (Higgins \& Sharp, 1988; Higgins et al., 1992). Distances between the sequences were calculated using the two-parameter model of Kimura (1980). Sites with gaps existing in any of the sequences were not included in the analysis. A phylogenetic tree was constructed by the neighbour-joining method of
Saitou \& Nei (1987). Bootstrap analysis was performed by taking 1000 random samples from the multiple alignment as described by Felsenstein (1985). This provided a measure of how well-supported parts of the tree are, given the data set and the method used to construct the tree. The tree was rooted using Physarum polycephalum as an outgroup.

\section{Results and Discussion}

The nucleotide sequence of the SSU rDNA as derived from genomic clones is shown in Fig. 1. The sequence is 1800 bases long. No variability was found between yeastand mycelial-phase cDNA clones. Unlike Plasmodium, $B$. dermatitidis does not appear to have phase-specific, structurally distinct small subunit ribosomes. Previous reports have suggested a ribosomal size difference between the yeast and mycelial phases in $B$. dermatitidis (Bawdon et al., 1984) and in the dimorphic fungus Histoplasma capsulatum (Gates \& Brownstein, 1980; Bawdon et al., 1984), and it is possible that differences in other components of the ribosome account for these observations. A number of point mutations which were not phase-specific were detected in the cDNA clones (data not shown), but only one, the base substitution at position 1352, could be demonstrated to be within the genome and not the result of reverse transcription or PCR amplification error. Heterogeneity has previously been described in the $5 \mathrm{~S}$ ribosomal subunit of several fungal species (Selker et al., 1985), but not in the 18S rRNA. The functional significance of this polymorphism is not known.

An evolutionary tree was derived from 1625 nucleotide bases which could be unambiguously aligned with the SSU rRNA sequences of fourteen other eukaryotic organisms (Fig. 2). This tree includes a broader range of fungi than prior publications containing phylogenetic analyses of SSU rRNA. B. dermatitidis is closely aligned with the Ascomycetes $N$. crassa and $P$. anserina. Ascomycetes are distinguished from other fungi primarily on the basis of their sac-like meiosporangia or asci, which usually contain four or eight haploid ascopores at maturity (Kendrick, 1985). Within the phylum Ascomycota, organisms have been further classified based on their type of ascus and the manner with which they discharge their ascospores (Kendrick, $1985)$. B. dermatitidis has protunicate asci which disintegrate prior to the release of ascospores. $N$. crassa and $P$. anserina both contain unitunicate-inoperculate asci which are single-walled and contain lids which open at maturity, allowing the ascospores to be ejected. The presence of $B$. dermatitidis on a separate branch of the dendrogram from $N$. crassa and $P$. anserina is thus supported by previous classification schemes based on morphological criteria. 


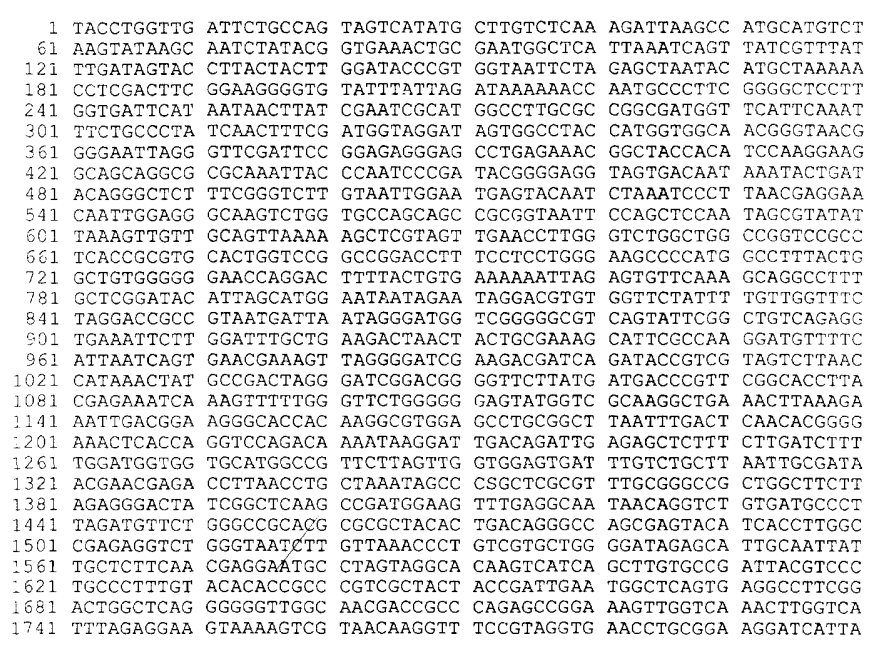

Fig. 1. The nucleotide sequence of the SSU rRNA gene of Blastomyces dermatitidis.

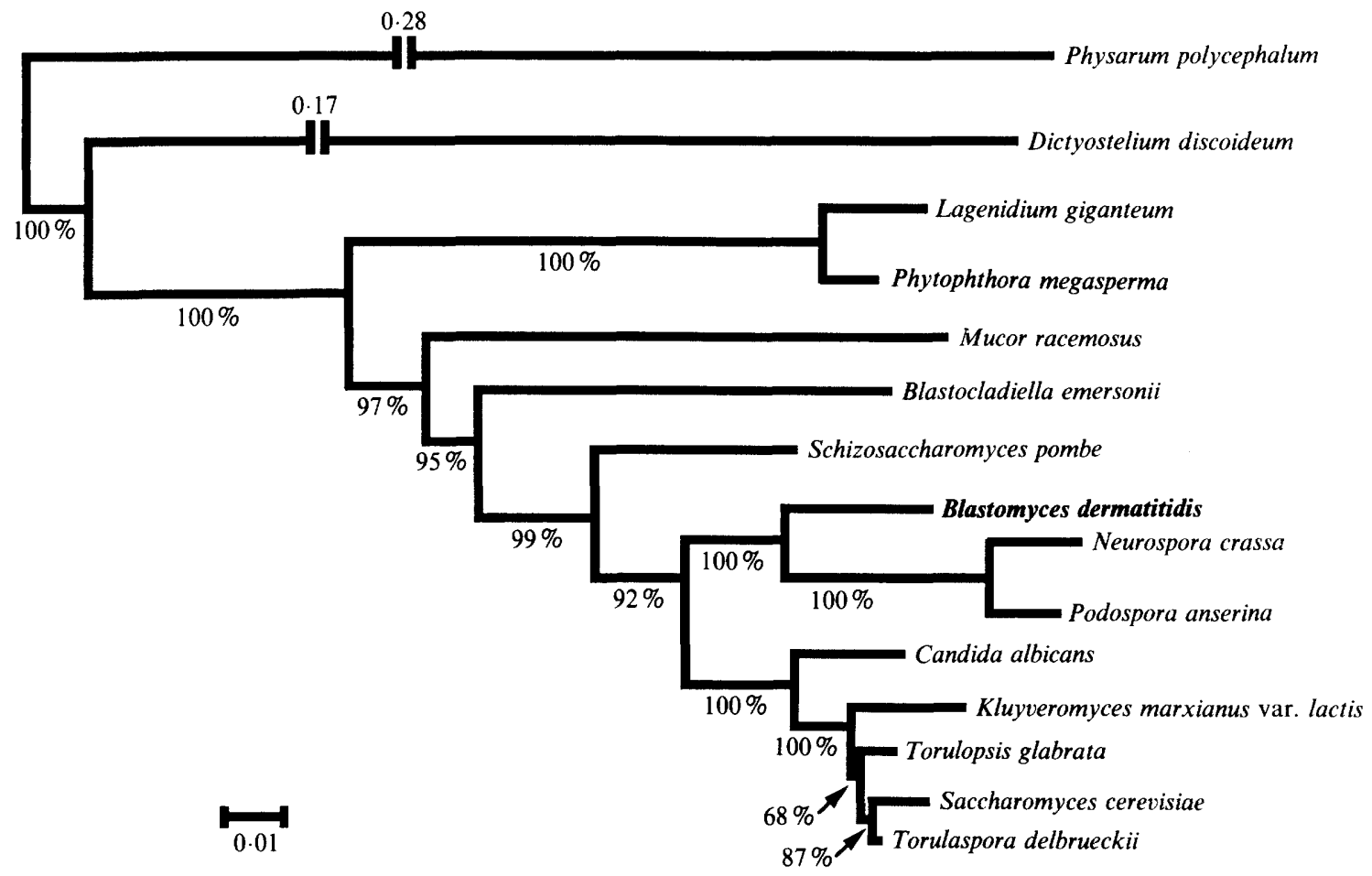

Fig. 2. Evolutionary tree based on the SSU rRNA sequences of fifteen eukaryotic organisms. Evolutionary distance between organisms is indicated by the horizontal branch length, which reflects the number of nucleotide substitutions per site along that branch from node to endpoint. Where the branches are not drawn to scale, numbers reflecting the branch length are given above the branch. Percentage of bootstrap samplings, derived from 1000 samples, supporting the interior branches are given below these branches.

Members of the genera Candida and Torulopsis lack a sexual cycle and have been grouped with other imperfect fungi in the phylum Deuteromycota. Based on physiological criteria, Candida and Torulopsis appear closely related to the Ascomycetes and are felt to have evolved from an Ascomycote ancestor following the loss of a sexual state. 5S rRNA (Chen et al., 1984) and 18S rRNA
(Hendriks et al., 1989; Barns et al., 1991) sequence data support the close affiliation of these yeasts with the Ascomycetes. These same studies demonstrate a close evolutionary relationship between $K$. marxianus var. lactis and $S$. cerevisiae. $18 \mathrm{~S}$ rRNA sequence analysis has shown $T$. glabrata to be more closely related to $S$. cerevisiae than to C. albicans (Barns et al., 1991), which 
favours maintaining Torulopsis in a genus distinct from Candida. Our dendrogram confirms these observations, and supports the close evolutionary relationship between $S$. cerevisiae and $T$. delbrueckii demonstrated in the recent analysis by Hendriks et al. (1991). Based on ribosomal sequence data, the genera Candida, Torulopsis, Torulaspora, Kluyveromyces and Saccharomyces can appropriately be placed in the class Saccharomycetes, order Endomycetales.

$S$. pombe is an ascosporogenous yeast which, based on morphological criteria, has been grouped with $S$. cerevisiae within the family Saccharomycetaceae. $S$. pombe's position between $B$. dermatitidis and $B$. emersonii in our dendrogram, which is well-supported by bootstrap analysis, conflicts with this taxonomic assignment. Sequence analysis of 5S RNA, however, places $S$. pombe in a distant relationship with $S$. cerevisiae, aligning it more closely with the Zygomycetes and Chytridiomycetes (Huysman et al., 1983). S. pombe differs from $S$. cerevisiae in that it multiplies by binary fission, as opposed to budding. At a molecular level, the two yeasts differ in (1) the regulation of gene transcription, (2) autonomously replicating sequences, (3) ras gene structure and protein function, and (4) the mitotic cell cycle (reviewed by Russell \& Nurse, 1986). Our dendrogram supports the hypothesis that the phylogenetic relationship between $S$. pombe and $S$. cerevisiae is more distant than has been previously thought.

The divergence of the Zygomycete $M$. racemosus prior to the Chytridiomycete $B$. emersonii was unexpected. When the fungi were given their own kingdom by Whittaker (1959), he placed the Chytridiomycetes in this kingdom and suggested that the Zygomycetes had evolved from a Chytridiomycete by loss of cilia (Whittaker, 1969). He later removed the Chytridiomycetes from the Fungal kingdom and placed them in the Protoctista kingdom (Whittaker \& Margulis, 1978). Cavalier-Smith (1981), who advocates a seven-kingdom classification of eukaryotic organisms that does not recognize the Protoctista kingdom, places the Chytridiomycetes in the kingdom Fungi, phylum Archemycota. The Zygomycetes and other non-ciliated higher fungi are proposed to have evolved from a ciliofungal ancestor (Cavalier-Smith, 1987). While a close phylogenetic relationship between the Chytridiomycetes and higher fungi is supported by recent SSU rRNA sequence analysis (Foerster et al., 1990), the ancestral relationships of the Zygomycetes and the Chytridiomycetes remain unknown.

The two Oomycetes, Lagenidium giganteum and Phytophthora megasperma, form a monophyletic group in agreement with previous SSU rRNA analysis (Foerster et al., 1990). There has been much speculation regarding the phylogenetic relationship of the Oomycetes and fungi. The Oomycetes have been variously grouped with the higher fungi (Whittaker, 1959), the Protoctista (Margulis, 1988), and with the chromophyte algae in the plant kingdom Chromista (Cavalier-Smith, 1981). Recent SSU rRNA sequence analysis supports this latter classification.

As other analyses of SSU rRNA sequences of fungi are completed, dendrograms such as that reported here with $B$. dermatitidis should become increasingly helpful in fungal systematics.

The authors thank K. J. Kwon-Chung and M. Geber for their review of the manuscript, $O$. Gigliotti for his technical assistance, and C. Bennett for his help in the preparation of this manuscript.

\section{References}

Barns, S. M., Lane, D. J., Sogin, M. L., Bibeau, C. \& Weisburg, W. G. (1991). Evolutionary relationships among pathogenic Candida species and relatives. Journal of Bacteriology 173, $2250-2255$.

Bawdon, R. E., Fishkin, A. M. \& Garrison, R. G. (1984). Ultrastructure aspects of cytoplasm ribosomes from Histoplasma capsulatum and Blastomyces dermatitidis as revealed by heavy metal staining. Mycopathologia 86, 155-163.

Cavalier-Smith, T. (1981). Eukaryotic kingdoms: seven or nine? BioSystems 14, 461-481.

Cavalier-Smith, T. (1987). The origin of fungi and pseudofungi. In Evolutionary Biology of the Fungi, pp. 339-353. Edited by A. D. M. Rayner, C. M. Brasier \& D. Moore. Cambridge: Cambridge University Press.

Chen, M. W., Anne, J., Volckaert, G., Huysman, E., VandenBERGHE, A. \& DE WACHTER, R. (1984). The nucleotide sequences of the $5 \mathrm{~S}$ rRNAs of seven molds and a yeast and their use in studying ascomycete phylogeny. Nucleic Acids Research 12, 4881-4892.

ChomczYNSKI, P. \& SACCHI, M. (1987). Single-step method of RNA isolation by acid guanidinium thiocyanate-phenol-chloroform extraction. Analytical Biochemistry 162, 156-159.

FelsensteIn, J. (1985). Confidence limits on phylogenies: an approach using the bootstrap. Evolution 39, 783-791.

Foerster, H., Coffey, M. D., Ellwood, H. \& SogIN, M. L. (1990). Sequence analysis of the small subunit ribosomal RNAs of three zoosporic fungi and implications for fungal evolution. Mycologia $\mathbf{8 2}$, 306-312.

Gates, D. W. \& Brownstein, B. H. (1980). Ribosomal RNA from the yeast and mycelial phases of Histoplasma capsulatum. Experimental Mycology 4, 231-238.

Gunderson, J. H., Ellwood, H., Ingold, A., Kindle, K. \& Sogin, M. L. (1987a). Phylogenetic relationships between chlorophytes, chrysophytes, and Oomycetes. Proceedings of the National Academy of Sciences of the United States of America 84, 5823-5827.

Gunderson, J. H., Sogin, M. L., Wollet, G., Hollingdale, M., DE la Cruz, V. F., Waters, A. P. \& McCutchan, T. F. (1987b). Structurally distinct, stage specific ribosomes occur in Plasmodium. Science 238, 933-937.

Hendriks, L., Goris, A., Neefs, J. M., Van de Peer, Y., Hennebert, G. \& DE WACHTER, R. (1989). The nucleotide sequence of the yeast Candida albicans and the evolutionary position of the fungi among Eukaryotes. Systems of Applied Microbiology 12, 223-229.

Hendriks, L., GoRIS, A., DE BRUYN, K. \& DE WAChTER, R. (1990). The nucleotide sequence of the small ribosomal subunit RNA of the yeast Torulaspora delbrueckii. Nucleic Acid Research 18, 4611.

Hendriks, L., Goris, A., Van de Peer, Y., Neefs, J. M., Vancanneyt, M., Kersters, K., Hennebert, G. L. \& DE WACHTER, R. (1991). Phylogenetic analysis of five medically important Candida species as deduced on the basis of small 
ribosomal subunit RNA sequences. Journal of General Microbiology 137, 1223-1230.

Higgins, D. G. \& Sharp, P. M. (1988). Clustal: a package for performing multiple sequence alignment on a microcomputer. Gene $73,237-244$

Higgins, D. G., Bleasby, A. J. \& Fuchs, R. (1992). Clustal v: improved software for multiple sequence alignment. Computer Applications for Biosciences 8 , in the Press.

Holmes, D. S. \& QuigleY, M. (1981). A rapid boiling method for the preparation of bacterial plasmids. Analytical Biochemistry 114, 193-197.

Huysmans, E., Dams, E., Vandenberghe, A. \& De Wachter, R. (1983). The nucleotide sequences of the 5S rRNAs of four mushrooms and their use in studying the phylogenetic position of the basidiomycetes among the eukaryotes. Nucleic Acids Research 11, 2871-2880.

Johansen, T., Johansen, S. \& Haugli, F. B. (1988). Nucleotide sequence of Physarum polycephalum small subunit ribosomal RNA as inferred from the gene sequence:"secondary structure and evolutionary implications. Current Genetics 14, 265-273.

KaNetSUNA, F. \& CARBONELL, L. M. (1971). Cell wall composition of yeastlike and mycelial forms of Blastomyces dermatitidis. Journal of Bacteriology 16, 946-948.

Kendrick, B. (1985). True fungi - (2) Phylum Dikaryomycota (A) Subphylum Ascomycotina. In The Fifth Kingdom, pp. 21-72. Ontario: Mycologue Publications.

KIMURA, M. (1980). A simple method for estimating evolutionary rates of base substitutions through comparative studies of nucleotide sequences. Journal of Molecular Evolution 16, 111-120.

LEVINE, S. \& ORDAL, Z. J. (1949). Factors influencing the morphology of Blastomyces dermatitidis. Journal of Bacteriology 52, 687-694.

McCarroll, R. G., Olsen, G. J., Stahl, Y. D., Woese, C. R. \& SoGIN, M. L. (1983). Nucleotide sequence of the Dictyostelium discoideum small-subunit ribosomal ribonucleic acid inferred from the gene sequence: evolutionary implications. Biochemistry 22, 5858-5868.

MaleszKa, R. \& Clark-WalKer, G. D. (1990). Sequence of the gene for the cytoplasmic ribosomal RNA small subunit from Kluyveromyces lactis. Nucleic Acids Research 18, 1889.

Margulis, L. \& Schwartz, K. V. (1988). Oomycota. In Five Kingdoms: An Illustrated Guide to the Phyla of Life on Earth, pp. 142-149. New York: W. H. Freeman \& Co.

Nickerson, W. J. \& Edwards, G. A. (1949). Studies on the physiological basis of morphogenesis in fungi. I. The respiratory metabolism of dimorphic pathogenic fungi. Journal of General Physiology 33, 41-55.
Olsen, G. J., Lane, D. J., Grovannoni, S. J. \& Pace, N. R. (1986). Microbial ecology and evolution: a ribosomal RNA approach. Annual Review of Microbiology 40, 337-365.

Price, C. W., Fuson, G. B. \& Phaff, H. J. (1978). Genome comparison in yeast systematics: delimitation of species within the genera Schwanniomyces, Saccharomyces, Debaryomyces, and Pichia. Microbiology Reviews 42, 161-193.

RoY, I. \& LANDAU, J. W. (1972). Protein constituents of cell walls of the dimorphic phases of Blastomyces dermatitidis. Canadian Journal of Microbiology 18, 473-478.

RubTsov, P. M., Musakhanov, M. M., Zakharyev, V. M., Krayev, A. S., Skyrabin, K. G. \& Bayev, A. A. (1980). The structure of the yeast ribosomal genes. 1 . The complete nucleotide sequence of the 18S ribosomal RNA gene from Saccharomyces cerevisiae. Nucleic Acids Research 8, 5779-5794.

RUSSELl, P. \& NURSE, P. (1986). Schizosaccharomyces pombe and Saccharomyces cerevisiae: a look at yeasts divided. Cell 45, 781-782.

SaITOU, N. \& NeI, M. (1987). The neighbor-joining method: a new method for reconstructing phylogenetic trees. Molecular and Biological Evolution 4, 406-425.

Sambrook, J., Fritsch, E. F. \& Maniatis, T. (1989). Molecular Cloning: A Laboratory Manual, 2nd edn. Cold Spring Harbor, New York: Cold Spring Harbor Laboratory.

Selker, E. U., Stevens, J. N. \& Metzenberg, R. L. (1985). Heterogeneity of SS RNA in fungal ribosomes. Science 227, 1340-1343.

Sogin, M. L., Miotto, K. \& Miller, L. (1986). Primary structure of the Neurospora crassa small unit ribosomal RNA coding region. Nucleic Acids Research 14, 9540.

SOUTHERN, E. M. (1975). Detection of specific sequences among DNA fragments separated by gel electrophoresis. Journal of Molecular Biology 98, 503-517.

TAYLOR, J. J. (1961). Nucleic acids and dimorphism in Blastomyces. Experimental Cell Research 24, 155-158.

WhITTAKER, R. H. (1959). On the broad classification of organisms. Quarterly Review of Biology 34, 210-236.

WHITAKER, R. H. (1969). New concepts of kingdoms of organisms. Science 163, 150-160.

Whittaker, R. H. \& Margulis, L. (1978). Protist classification and the kingdoms of organisms. BioSystems 10, 3-18.

Wong, O. C. \& Clark-Walker, G. D. (1990). Sequence of the gene for the cytoplasmic ribosomal RNA small subunit from Candida (Torulopsis) glabrata. Nucleic Acids Research 18, 1888. 